\title{
Tank Waste Remediation System Decision Guide
}
M. A. Robershotte
A. J. Brothers
L. L. Dirks
M. S. Madden
D. A. Seaver

June 1995

Prepared for the U.S. Department of Energy under Contract DE-AC06-76RLO 1830

Pacific Northwest Laboratory.

Operated for the U.S. Department of Energy by Battelle Memorial Institute 


\section{DISCLAIMER}

Portions of this document may be illegible in electronic image products. Images are produced from the best available original document. 
PNL-10589

UC-

2030

\title{
Tank Waste Remediation System Guide
}

\author{
M. A. Robershotte \\ L. L. Dirks \\ D. A. Seaver \\ A. J. Bothers \\ M. S. Madden
}

June 1995

Prepared for

the U.S. Department of Energy

under Contract DE-AC06-76RLO 1830

Pacific Northwest Laboratory

Richland, Washington 99352 


\section{SUMMARY}

The scope, number and complexity of Tank Waste Remediation System (TWRS) decisions require an integrated, consistent, and logical approach to decision making. TWRS has adopted a seven-step decision process applicable to all decisions. Not all decisions, however, require the same degree of rigor/detail. The decision impact will dictate the appropriate required detail. In the entire process, values, both from the public as well as from the decision makers, play a key role. This document concludes with a general discussion of the implementation process that includes the roles of concerned parties. 


.




\section{CONTENTS}

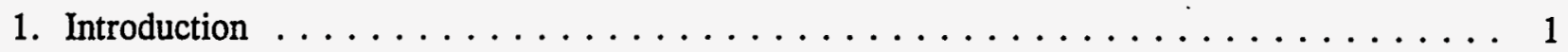

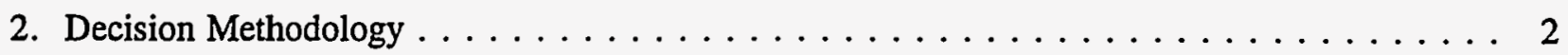

2.1 Define the Frame of the Decision $\ldots \ldots \ldots \ldots \ldots \ldots \ldots \ldots \ldots$

2.2 State Issues $\ldots \ldots \ldots \ldots \ldots \ldots \ldots \ldots \ldots \ldots \ldots \ldots \ldots \ldots$

2.3 Develop a Set of Alternatives $\ldots \ldots \ldots \ldots \ldots \ldots \ldots \ldots \ldots \ldots$

2.4 Formulate Decision Values $\ldots \ldots \ldots \ldots \ldots \ldots \ldots \ldots \ldots \ldots$

2.5 Translate Decision Values into a Set of Measures $\ldots \ldots \ldots \ldots \ldots \ldots \ldots$

2.6 Analyze and Evaluate Alternatives $\ldots \ldots \ldots \ldots \ldots \ldots \ldots \ldots$

2.7 Make a Decision $\ldots \ldots \ldots \ldots \ldots \ldots \ldots \ldots \ldots \ldots \ldots \ldots \ldots$

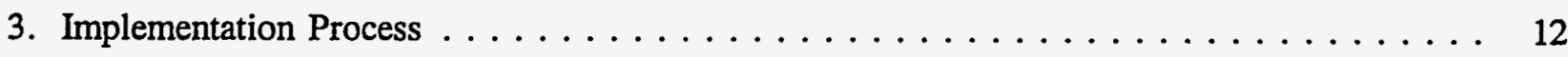

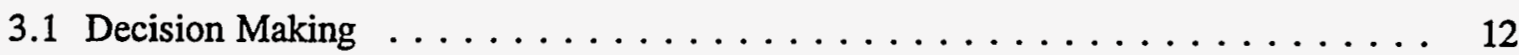

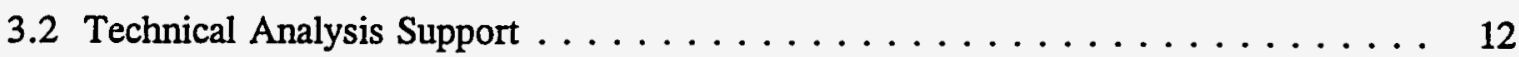

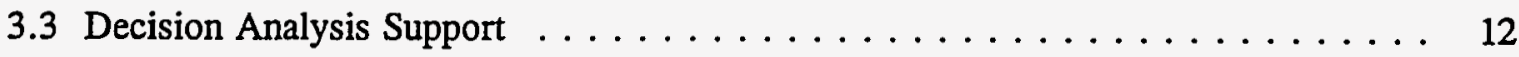

3.4 TWRS Implementation $\ldots \ldots \ldots \ldots \ldots \ldots \ldots \ldots \ldots \ldots \ldots \ldots$

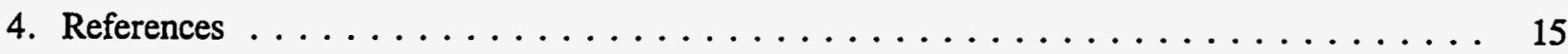

Appendix A - Alternatives-by Values Matrix $\ldots \ldots \ldots \ldots \ldots \ldots \ldots \ldots \ldots$ A-1 


\section{FIGURES}

1. High-Level Value Tree for TWRS Ends Values $\ldots \ldots \ldots \ldots \ldots \ldots \ldots \ldots$

2. High-Level Value Tree for TWRS Means Values $\ldots \ldots \ldots \ldots \ldots \ldots \ldots \ldots \ldots$

3. High-Level Value Tree for TWRS Process Values $\ldots \ldots \ldots \ldots \ldots \ldots \ldots \ldots$

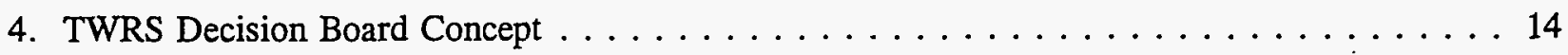




\section{TWRS Decision Guide}

\section{Introduction}

The Tank Waste Remediation System (TWRS) Program is responsible for the safe storage, retrieval, treatment, and preparation for disposal of high-level waste currently stored in underground storage tanks at the Hanford Site in Richland, Washington and the disposal of low-level waste. To ensure that the mission is carried out successfully and safely, the TWRS program has adopted a systems engineering approach that incorporates public values and analytical methods into the decision-making process. The decision-making process addresses TWRS architecture decisions and is comprised of a methodology for analyzing decisions and an implementation process that defines responsibilities. The methodology has been defined by TWRS in seven major steps: 1) define the frame of the decision; 2) state issues; 3) develop a set of alternatives; 4) formulate decision values; 5) translate decision values into sets of measures; 6) analyze and evaluate alternatives; and 7) make a decision. Individuals responsible for analyzing information, making decisions and defending the results of the decisions must participate in various stages of the decision-making process.

The magnitude, scope, and complexity of the TWRS program requires that vast numbers of decisions be made. To classify Hanford waste decisions, a decision coding system has been developed based on the Tank Waste Remediation System Functions and Requirements, DOE/RL-92-60 REV 1. Level 1 decisions are the highest level strategic decisions. Levels 2 through $\mathrm{X}$ are subordinate related decisions. Each decision is linked to a TWRS function identified by systems engineering. Tank Waste Remediation System Decisions and Risk Assessment (WHC-EP-0786) (Johnson 1994) defines decisions for the top four levels of functions. To ensure that the process for making these decisions is logical, defensible, consistent, and flexible enough to deal with dynamic conditions, further guidance is necessary. This document, which is targeted to managers and technical staff in the TWRS program, provides that guidance, but does not define those responsible for making the various TWRS decisions. This document is intended to supplement the TWRS Systems Engineering Desk Instruction, Trade Study/Decision Analysis (WHC-IP-1101, TWRS-SE-4) (WHC 1994a) and provide more detailed methodological information.

Although the seven steps will pertain to all decisions, the specifics for what is required to satisfy the steps may be much less than what is described in this guide. The level of detail presented in this guide would be appropriate for higher-level decisions, but may be more than what is required for virtually all lower-level and many mid-level decisions. A graded approach will be taken with the sophistication and detail of the process appropriately matched to the level and complexity of the decisions. 


\section{Decision Methodology}

The TWRS Program has adopted a seven-step, decision-making methodology. Although described as steps one through seven, the process is rarely linear. This process is usually highly iterative and often includes steps being taken in parallel (e.g., developing alternatives and formulating values), not sequentially.

\subsection{Define the Frame of the Decision}

The decision frame consists of the initial alternatives, values, information and methodology used in the analysis of a decision. Values or objectives are what is thought to be at stake in the decision outcome that should be considered in the evaluation of alternatives. Alternatives are the various courses of action that are available. Information is what is known about the expected impact of alternatives on values. The methodology uses the information to relate the alternatives and values in a way that makes it possible to arrive at a decision. Framing consists of identifying the decision and its preliminary alternatives, the relationship to other decisions, and specifying a set of basic objectives that are appropriate to the decision at hand.

For complex decision situations it can be valuable to develop a decision logic to put decisions in a context that shows their relationship with other decisions. Decision logic is a way of representing the relationships among decisions. The decision logic would have at its top, the high-level strategic or policy decisions, and at its bottom, the technical decisions that may not require a formal evaluation. Many of these high-level policy decisions may be assumptions for the decision at hand, and the technical decisions are necessary for a complete description of the decision alternatives. The hierarchial structure arises due to the fact that at the highest level, there are the fewest number of decisions, and at the lowest level, there are many technical decisions. Developing a decision logic frames the decision in the context of related decisions.

Defining the appropriate frame for the decision is certainly one of the most important steps in the entire decision process, because how the decision is framed either allows or eliminates certain classes of solutions. The decision frame is normally defined by the question that requires resolution. The specific decision to be analyzed is identified and a clear statement of the decision is formed. This step also defines the areas not being addressed by the decision at hand (e.g., higher-level strategy decisions). This framing process may also lead to the structuring or restructuring of other decisions to be addressed at a later time.

The decision statement is often formulated as a question; for example, "What type of subsurface barrier should be adopted?" This decision frame indicates that some type of subsurface barrier is actually required, which may or may not be the case. The frame of the decision must be consciously and carefully defined. A recurrent problem in defining the decision frame is that the problem statement can be shifted from one level to another by moving from broader to narrower definitions and vice versa. This problem, along with two ideas to help in framing decisions (developing a values-byalternatives matrix and conducting a framing conference), is discussed in Section 5.1 of the draft 
Creighton et al. report (1995). Typically, the decision statement, if formed as a question, should not require a single, simple yes/no answer. It could, however, require a two-part answer; e.g., "What is the feasibility and advisability of constructing subsurface barriers?"

Other boundaries of the decision problem must also be clearly defined. These boundaries could include regulatory requirements; desires or key thresholds from stakeholders; and a definitive decision scope. In defining which broad classes of alternatives may be acceptable, the decision framers should consider the major concerns and values of the public and of stakeholders who may be affected by the decision and of champions (for or against) and their reasons for supporting or opposing the major decision alternatives.

Also included in this key decision step is an examination of related higher- and lower-level decisions to ensure the decision at hand has been defined consistent with these decisions. In addition, a determination is required as to what, if any, other decisions are so interdependent that they must all be addressed together. An example of this is the facility concepts for pretreatment, low-level vitrification, and high-level vitrification. These facility concepts are so interdependent that they must be addressed together, not as independent decisions.

\subsection{State Issues}

In many ways the state issues decision step is a continuation and refinement of the decision-framing step. Open issues are identified for clarification and/or study. Any remaining uncertain boundary limits are clarified and higher order decisions are identified and reexamined. Key assumptions are listed; the validity of these assumptions must be continually verified as the decision process passes through later steps. An important issue is whether there are any uncertainties that bear upon the decision outcome. These critical uncertainties should be explicitly highlighted at this step. Important definitions are also developed and approved; for example, defining how the concerned parties would define success, etc. If the results of the decision-framing step are very clean and straightforward, all that may be needed at this step is a listing of open issues, clarifying assumptions, and the definitions of key terms.

It is necessary to develop and compile the lists of issues, boundary limits, assumptions, and definitions, as well as review higher- and lower-level decisions to ensure the chosen decision frame is consistent and in consonance with these other decisions. The decision makers would review and approve, or provide further guidance and direction. Concerned stakeholders may wish to be involved at the issues step or may wish only to be informed of the results.

\subsection{Develop a Set of Alternatives}

The framing step defines the broad categories of alternatives for consideration and determines the breadth and the depth of these alternatives. The next step is to define a specific set of alternatives in detail. The possible alternatives (problem solutions) selected must satisfy the boundaries of the specific decision by complying with all requirements; however, when alternatives are initially being generated, 
no particular attention should be paid to the immediate feasibility of any proposed alternative. At this ideational stage, a rich and creative set of alternatives will be developed. In this way, potentially excellent alternatives are not prematurely discarded when their benefits might still be achieved with only slight adjustments. These adjustments could be in the form of a design change or relaxation of a constraint (e.g., regulatory modifications or waivers).

A useful tool for describing decisions is a strategy table. The strategy table is valuable when the decision being considered is of a complex nature and actually consists of a collection of decisions. A choice of alternatives for each of the individual decisions when taken together make up a strategy, which is the unit that is being evaluated. The strategy can be represented in a matrix in which the rows are the individual decisions and the columns are the alternatives that are available. A selection of a single alternative from each of the rows defines a strategy. The use of a strategy table facilitates a clear description of each alternative to be evaluated.

Two approaches that are helpful in generating alternatives are the combinatorial approach and the value-focused approach. In the combinatorial approach, TWRS managers and technical staff would identify the significant factors that distinguish among alternatives and define all possible combinations as alternatives. The other approach is to generate alternatives by values. In this approach, managers, technical staff, and stakeholder groups would be challenged to create alternatives that satisfy a particular set of values, without particular regard for how the alternatives affect other values. (More details on these two approaches are found in Section 5.3 of the Creighton Report.) The set of alternatives does not have to be an exhaustive list, but must represent the interests of stakeholder groups and the public at large.

It is necessary to work with TWRS managers, the technical staff and, when appropriate, the stakeholders to develop the set of alternatives. The technical staff will provide its list of alternatives and specific "stakeholder" alternatives will be added. The decision makers review, add or remove options, and ultimately confirm the set of alternatives to be evaluated.

\subsection{Formulate Decision Values}

Hanford decision making cannot be conducted without consideration of the values of the stakeholders and the public. Therefore, essential information on stakeholder values must be incorporated in the early stages of the decision-making process. Values are generally stated by stakeholder groups in very qualitative terms, making it somewhat difficult to determine when and if a particular decision has achieved a value. Difficulties also arise in determining which values are affected by particular decisions.

A mechanism for methodically incorporating stakeholder values in TWRS decision making has been developed and documented in Armacost et al. (1994), which provides a master list of values and suggests uses of such information. This master list of values was developed by first reviewing the

existing documents that include expressions of value related to TWRS. A list of all value-related statements in these documents was compiled. The high-level values were identified, as stated by the 
major organizations related to TWRS, and then separated into ends, means, and process values (see Figures 1 through 3). Ends values are important in and of themselves, no further justification is required. Means values ultimately support an ends value(s) (e.g., waste minimization is a means value that contributes to protecting human health and safety and protecting the environment). Process values indicate how the decision process should be performed (e.g., involve the public in decision making). The shaded boxes correspond to values expressions documented by the Hanford Tank Waste Task Force and the Hanford Future Site Uses Working Group. The numbers within each box refer to the value statements listed in Armacost et al. (1994). The shaded values were taken verbatim from The Future for Hanford: Uses and Cleanup (Working Group 1992) and The Hanford Tank Waste Task Force (HTWTF 1993) documents. These documents were given special attention as they involved public debate before publication. The method of using this information in the TWRS decision process follows:

1. From the list of high-level values (Figures 1 through 3) select those that apply to the decision. The intent is to obtain as comprehensive a list of values as possible, such that it may not be necessary to solicit values from stakeholders for each new decision.

2. Evaluate this list and determine which values differentiate among alternatives and what, if any, additional values are relevant?

3. Create the list of values relevant to the decision.

The formulation of decision values will require input from stakeholder groups. This may include additional values not previously or directly stated by stakeholders. The intent is not to require that the stakeholders convene and provide insights into what values are of importance for each decision. Instead, the master set of values (Armacost et al. 1994) will be used whenever appropriate to obtain value information. There is a requirement to identify the values that could impact a particular decision by differentiating among alternatives. This information will then be presented to the decision makers for review and confirmation.

\subsection{Translate Decision Values into a Set of Measures}

Once the values have been identified, ways of measuring each value must be determined. Measures are values that have been transformed from qualitative phrases into quantifiable terms, a necessary step toward measuring the performance of alternatives.

Measures fall into two main categories: natural and constructed. Natural measures already exist and are generally preferred over constructed measures. An example of a natural measure is the number and type of animals lost; such a measure directly supports the sub-value of protecting animals. Constructed measures consist of scenarios that describe different levels of performance on an objective or 


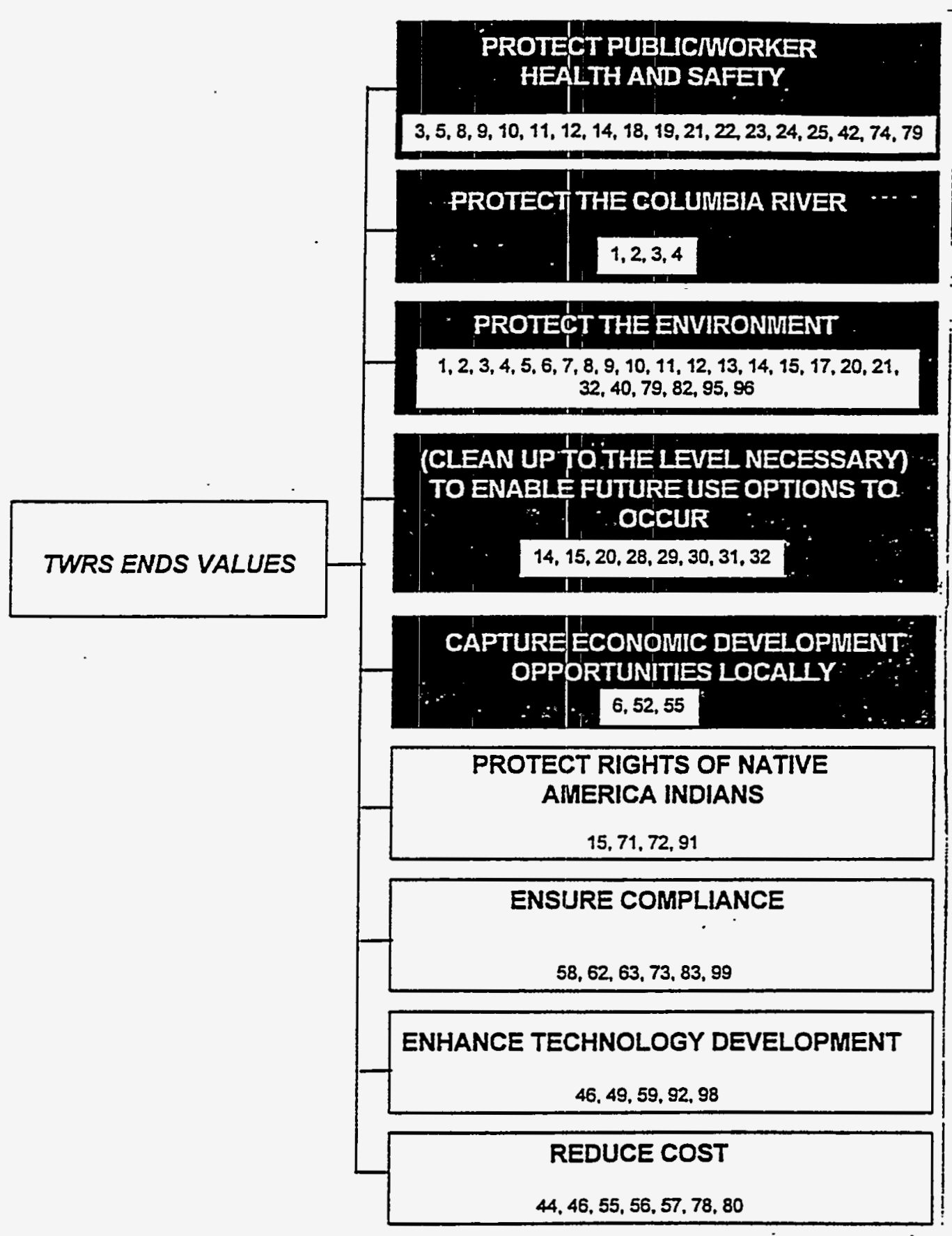

Figure 1. High-Level Value Tree for TWRS Ends Values 


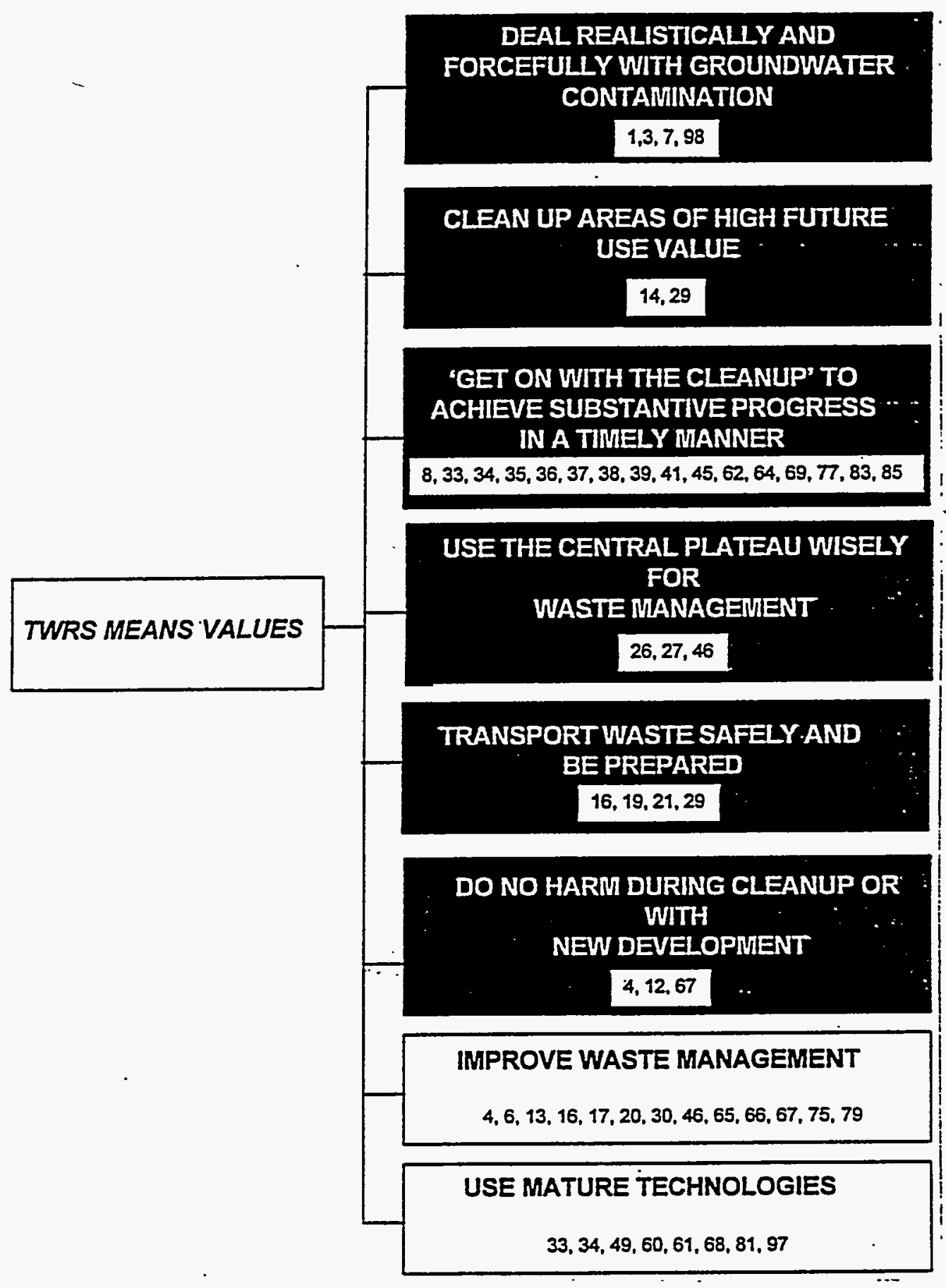

Figure 2. High-Level Value Tree for TWRS Means Values 


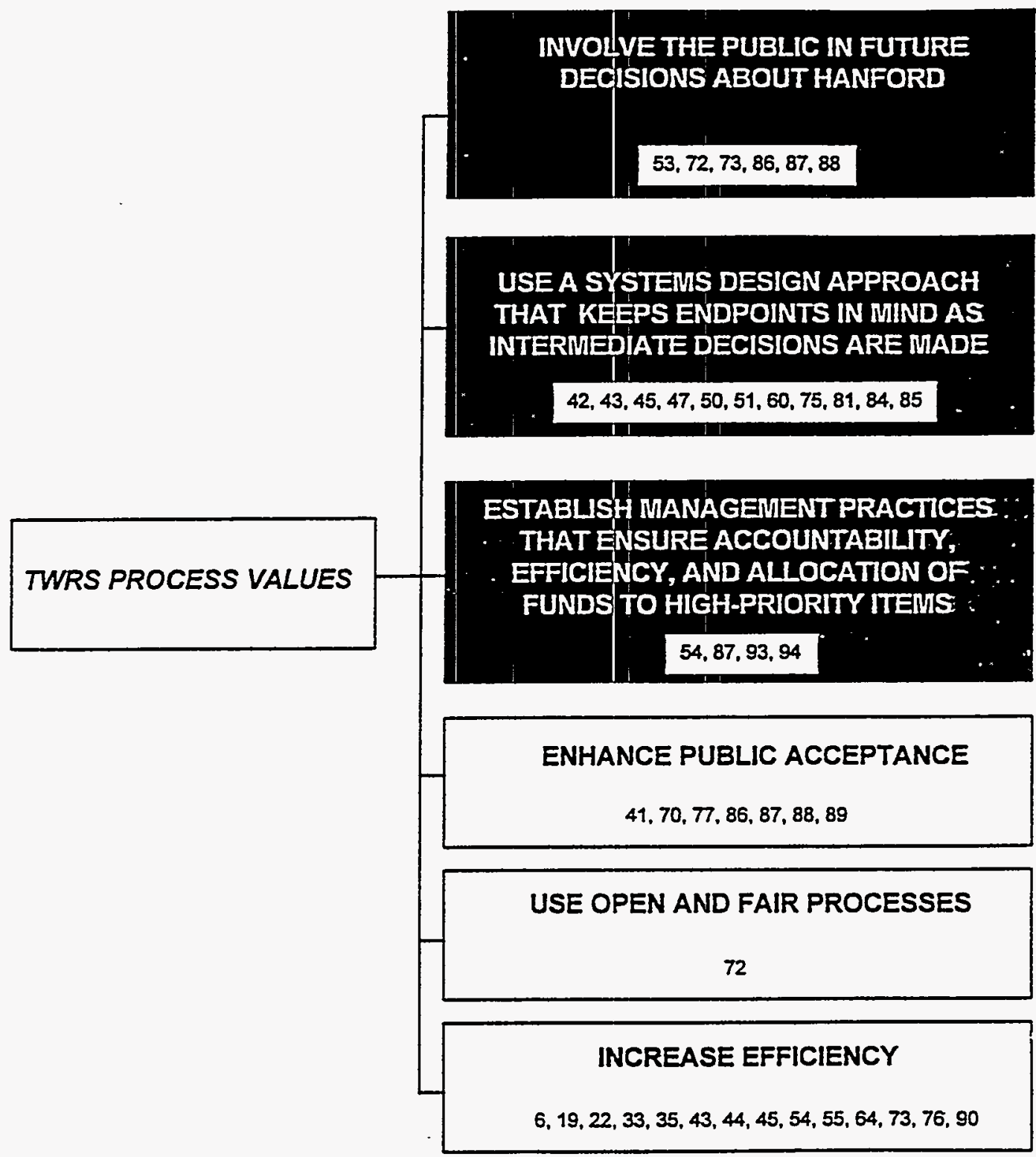

Figure 3. High-Level Value Tree for TWRS Process Values 
value. Constructed measures require that a scale be developed to indirectly measure how a value is achieved, e.g., developing a scale for evaluating the types of land that are lost to environmental cleanup. Certain land areas may be of higher value, and therefore would rate higher on the constructed scale; land with lower value would rate lower on the scale. For examples of specific measures that have been defined or developed, see Armacost et al. (1994). A particular value may have multiple measures, and the specific choice will depend upon the decision being evaluated.

\subsection{Analyze and Evaluate Alternatives}

Although analysis and evaluation are different functions, they are highly interrelated in a process that is usually iterative. In its simplest form, analysis provides alternative technical performance information and evaluation makes alternative comparisons. Analysis deals with the estimation of what will happen if an alternative is selected; evaluation deals with the estimation of the relative desirability of what is expected to happen. Analysis of alternatives is done first and is then followed by initial alternative evaluation. This frequently points out the need for further focused, or in-depth analysis before the alternatives can be evaluated again.

A precursor to alternative evaluation requires a thorough analysis of the feasible alternatives. After feasibility screening shortens the rich and creative list of generated alternatives, analysis of the remaining alternatives may proceed. Feasibility is a go/no-go decision, and may include physical/ technical, economic, financial, environmental, social, legal, and political factors. The analysis of a feasible alternative often includes determining the performance of the alternative in some model or technical engineering study. Analysis focuses on each individual alternative separately. As one moves into evaluation, a comparison of alternatives begins.

To evaluate each alternative, the technical analysis data are combined with the quantitative values information to determine how each alternative rates according to a defined set of value measures. Several methodologies. and tools exist to evaluate the information and generate results. Examples of these techniques are documented in Draft Methods for Analyzing and Communicating Technical and Value Information in the Tank Waste Remediation System Program (Creighton et al. 1995). Two options from that document are summarized below.

Alternatives can be evaluated by creating a values-by-alternative matrix. Each of the values that pertain to the decision at hand is identified in the left-hand column. A measure (e.g., dollars, waste volume generated, etc.) is chosen for each value to quantify or qualify that value. The alternatives being evaluated are listed across the top of the page. Within the matrix, the measure indicates how well each alternative addresses the value. This matrix allows a user to evaluate how well each alternative performs according to specific values. This tool is useful to decision makers and other stakeholders and, depending upon the nature of the data, may be enough information for all parties to reach a conciusion on the preferred alternative. 
The values-by-alternatives matrix represents the "facts" of the decision analysis. Typically, no single alternative will score highest on all the values. Consequently, the selection of an alternative will require tradeoffs be made on the relative importance of the objectives. This may be done on an informal level by the decision maker or a more formal process for eliciting weights may be employed. Decision makers would be asked to judge the relative importance of values. This information would then be combined with the values-by-alternatives matrix, and the alternatives would then be ranked according to the weights expressed by each group. This often requires aggregation of measures and conducting sensitivity analyses on weights for sets of measures before an alternative is selected.

Analysis and evaluation of alternatives may also require considerations of the uncertainty (risk) associated with the alternatives with respect to the values. It is important to be explicit about any uncertainty associated with the technical data estimates. The ranges of variability for technical data must be examined and the associated risks considered. In order to better understand the magnitude and impacts of these uncertainties on the outcomes of TWRS decisions, an approach that might be used involves modeling the decision and performing sensitivity analyses. This approach need not be strictly adhered to for every decision, but can be adapted to fit the requirements of the particular decision being analyzed.

The approach might entail the development and prioritization of a list of key issues relevant to the decision. A graphical representation of the key issues and the relationships among them and the uncertainties and outcome values could be developed. Using this qualitative model as a basis, a model that quantifies the key parameters and values of the decision could be developed. The quantitative model would produce point estimates of the key parameters which could be benchmarked against other data sources and model outputs. Sensitivity analyses could then be performed to determine which input values, varied within the range of their uncertainties, can have a significant impact on the output values of interest. Those input values would be treated as uncertain variables in subsequent analyses. Risk and decision analyses could then be performed, incorporating the uncertainties into the model (see WHC-IP-1103) (WHC 1994b). This would result in alternative performance expressed as a probability distribution rather than a point estimate. Consequently, the risks associated with the alternatives can be better assessed.

\subsection{Make a Decision}

Making the decision is the critical final step in the highly iterative seven-step process. To facilitate this, the analysis and evaluation results must be presented clearly and effectively. Not all decisions are handled formally and in the same manner. However, when the scope and complexity of the decision requires a formal and detailed approach is appropriate. The common basis for communicating to decision makers, as well as to the public, should be a clear presentation of the alternatives and values. Decision makers often want to know how the different stakeholder groups feel about the alternatives and what the implications are of the uncertainty in the analysis. This process is often best accomplished by the use of the alternatives-by-values matrix, including the estimates and uncertainty/risk information. To the extent that individuals or groups disagree with either the decision frame or the estimates, they are likely to disagree with the presentation of aggregate results or the sensitivity 
analyses. While the alternatives-by-values matrix is the heart of the analysis, it is often too detailed. Numerous tools and graphical methods for using, simplifying, and increasing the effectiveness of the results presentation are detailed in Section 7.0 of the Creighton Report (1995).

The analysis and evaluation information is presented and the specific strengths and weaknesses of the alternatives are identified. The decision makers may accept the results and make a decision, request more information, or require further analysis (perhaps with new specific guidance or changed assumptions).

Once the decision makers have chosen their favored alternative the decision is fully documented along with its basis. The decision makers will support the recommendation as the established Westinghouse Hanford Company (WHC) position. The decision makers then finalize agreement with the Department of Energy (DOE-RL) and other external parties, if appropriate. Additional communication with stakeholders may be required. This communication will emphasize how the various stakeholder values and concerns were considered in the decision process. 


\section{Implementation Process}

Implementation of the decision methodology defined above for specific decisions requires three functions: 1) decision making; 2) technical analysis support; and 3) decision analysis support. These functions are further defined below.

\subsection{Decision Making}

This function establishes the WHC position with respect to the decision being made. It includes the following:

- Active involvement in the decision structuring, including framing, identification of alternatives, and formulation of decision values.

- Oversight and guidance of the analysis producing the information to evaluate alternatives.

- Establishment and justification of the initial WHC TWRS Program position.

- Negotiation of the final decision with DOE-RL and other external parties.

\subsection{Technical Analysis Support}

This function conducts the analyses and provides the technical expertise necessary to produce the information needed to make the decision. Specific responsibilities include the following:

- Assistance to the decision makers in defining the decision frame, particularly what it includes and does not include, and related decisions and issues.

- Preliminary identification of potential alternatives.

- Preliminary identification of decision values and measures.

- Detailed analysis (e.g., with trade studies, modeling, etc.) to provide the information needed to evaluate alternatives and support decision making.

- Documentation of technical analyses.

- Technical assistance in documentation of decision basis.

\subsection{Decision Analysis Support}

This function performs a secretariat role for the decision makers and manages the decision process. Specific responsibilities include: 
- Identification and scheduling of decisions to be made.

- Facilitation of the decision structuring (e.g., framing; issue identification; and identification of alternatives, values and measures).

- Assistance in the interface between decision making and technical analysis support to ensure that needed information is produced and provided to the decision makers.

- Documentation of decisions made and their basis.

\subsection{TWRS Implementation}

The organizational responsibility for performing the above functions will depend on the specific decision to be made. A TWRS Decision Board has been established to perform the decision-making function for certain high-level, strategic decisions. This board consists of senior managers from the WHC TWRS Program and the Manager, Pacific Northwest Laboratory (PNL) TWRS Program. This board will focus on the key, high-level decisions (usually levels 1 through 4) and will review other decisions on a selective basis. To be appropriate for the Decision Board's attention, decisions must be of major impact to the program. Major impact decisions would be characterized by one or more of the following:

- Major milestones (either Tri-Party Agreement or others).

- Large cost.

- Significant public interest necessitating large-scale stakeholder involvement.

- High visibility or having significant strategic/policy direction implications (e.g., volume of highlevel waste).

- Potentially highly controversial.

- Cross cut multiple program areas (e.g., disposal, operations, technology development, etc.).

To assist the Decision Board with its mission, TWRS Systems Integration will perform the decision analysis support function, serving as TWRS decision support team to the Decision Board. The TWRS decision support team will establish the agenda for board meetings, ensure needed information is available, obtain needed expertise from appropriate organizations to support the decision process, facilitate board meetings, and document decisions made and their basis. Throughout the entire decision process, the TWRS decision support team will draw heavily on technical staff expertise from throughout the TWRS Program, particularly engineering (Figure 4). 


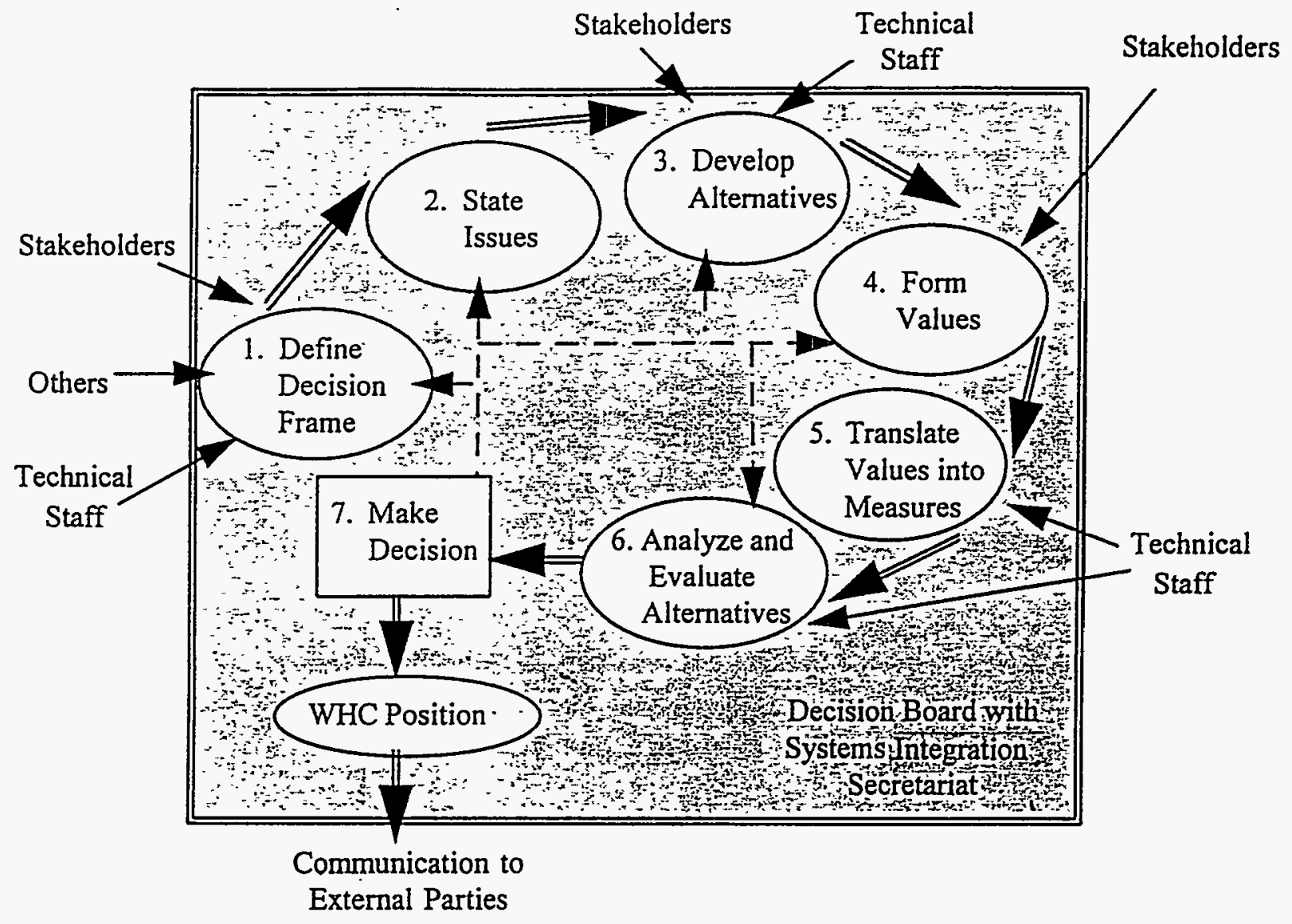

Figure 4. TWRS Decision Board Concept

Architecture selection decisions not made by the Decision Board are delegated to lower-level management, subject to approval by appropriate senior WHC TWRS management. The process and method for making these decisions will be as described above, with lower-level management substituting for the Decision Board and other technical staff rather than Systems Integration performing the decision analysis support function. WHC TWRS Engineering and Program Managers responsible for specific decisions are responsible for identifying appropriate decision makers. TWRS System Integration will provide guidance (such as this document) and assistance via consultation. 


\section{References}

Armacost, L. L., J. Creighton, M. A. Robershotte, D. von Winterfeldt. 1994. Public Values Related to Decisions in the Tank Waste Remediation System Program. PNL-10107, Pacific Northwest Laboratory, Richland, Washington.

Creighton, J., L. L. Dirks, M. A. Robershotte, D. von Winterfeldt. 1995. Draft Methods for Analyzing and Communicating Technical and Value Information in the Tank Waste Remediation System Program. Pacific Northwest Laboratory, Richland, Washington. [In process].

Hanford Tank Waste Task Force (HTWTF). 1993. Hanford Tank Waste Task Force (Final Report). Submitted by the Hanford Waste Tank Task Force to the Washington State Department of Ecology, U.S. Department of Energy, and U.S. Environmental Protection Agency.

Johnson, M. E. 1994. Tank Waste Remediation System Decisions and Risk Assessment. WHC-EP0786, Westinghouse Hanford Company, Richland, Washington.

Westinghouse Hanford Company (WHC). 1994a. Tank Waste Remediation System Systems Engineering Desk Instruction, Trade Study/Decision Analysis. WHC-IP-1101 TWRS-SE-4, Westinghouse Hanford Company, Richland, Washington.

Westinghouse Hanford Company (WHC). 1994b. Tank Waste Remediation System Systems Engineering Desk Instruction, Risk Management. WHC-IP-1103 TWRS-SE-6, Westinghouse Hanford Company, Richland, Washington.

Working Group (The Hanford Future Site Uses Working Group). 1992. The Future for Hanford: Uses and Cleanup. The Final Report of the Hanford Future Site Uses Working Group, Chairman Dr. Marshall E. Drummond, Eastern Washington University, Cheney, Washington.

U.S. Department of Energy Richland Operations Office (DOE-RL). Tank Waste Remediation System Functions and Requirements. DOE-RL-92-60 REV 1, Department of Energy Richland Operations Office, Richland, Washington. 


\section{Appendix A}

\section{Alternatives-by-Values Matrix}




\section{Appendix A}

\section{Alternatives-by-Values Matrix}

An example of a completed alternative-by-value matrix (Table 6.1 from Creighton et al. 1995) is presented below. Values are listed in rows; alternatives in the columns. Footnotes in the table indicate the measure for each value.

A-1 
Table 6.1. Alternatives by Values Matrix for the SSB Case (One Tank Farm, Illustration Only)

\begin{tabular}{|c|c|c|c|c|c|c|c|c|c|c|c|}
\hline Alternatives: & $\begin{array}{c}1 \\
\text { No } \\
\text { Action } \\
\text { No SSB }\end{array}$ & $\begin{array}{c}2 \\
\text { Surface } \\
\text { Barrier } \\
\text { No SSB }\end{array}$ & $\begin{array}{c}3 \\
\text { Trad. } \\
\text { Sluicing } \\
\text { No ssB }\end{array}$ & $\begin{array}{c}4 \\
\text { Robotic } \\
\text { Sluicing } \\
\text { No SSB }\end{array}$ & $\begin{array}{c}5 \\
\text { Mech. } \\
\text { Retrieval } \\
\text { No SSB }\end{array}$ & $\begin{array}{c}6 \\
\text { Close } \\
\text { Chemical } \\
\text { SSB \& } 3\end{array}$ & $\begin{array}{c}7 \\
\text { Box } \\
\text { Chemical } \\
\text { SSB \& } 3\end{array}$ & $\begin{array}{c}8 \\
\text { V-shaped } \\
\text { Chemical } \\
\text { SSB \& } 3\end{array}$ & $\begin{array}{c}9 \\
\text { V-shaped } \\
\text { Cryogenic } \\
\text { SSB \& } 3\end{array}$ & $\begin{array}{c}10 \\
\text { Desiccant } \\
\text { SSB \& } 3\end{array}$ & $\begin{array}{c}11 \\
\text { Sel. Cl. } \\
\text { Chem. } \\
\text { sSB \& } 3\end{array}$ \\
\hline $\begin{array}{l}\text { Public cumulative radiological } \\
\text { risk (1) }\end{array}$ & 32 & 2.5 & 0.19 & 0.14 & 0.45 & 0.10 & 0.10 & 0.10 & 0.10 & 0.10 & 0.15 \\
\hline Public cumulative toxic risk (2) & 500 & 3 & 1 & 0.03 & 0.1 & 0.03 & 0.03 & 0.03 & 0.03 & 0.03 & 0.5 \\
\hline Worker radiological risk (3) & 0.00 & 0.01 & 0.05 & 0.01 & 0.02 & 0.10 & 0.10 & 0.10 & 0.10 & 0.10 & 0.10 \\
\hline Worker toxic risk (4) & 0.00 & 0.02 & 0.10 & 0.02 & 0.04 & 0.20 & 0.20 & 0.20 & 0.20 & 0.20 & 0.20 \\
\hline $\begin{array}{l}\text { Percent removal of rad and haz. } \\
\text { mats }\end{array}$ & $0 \%$ & $50 \%$ & $99 \%$ & $100 \%$ & $95 \%$ & $99 \%$ & $99 \%$ & $99 \%$ & $99 \%$ & $99 \%$ & $99 \%$ \\
\hline Delay in clean up & n.a. & $\mathbf{0}$ & $\mathbf{0}$ & 1 & 1 & 2 & 2 & 2 & 2 & 2 & 2 \\
\hline Compliance (5) & $\begin{array}{c}\text { Major } \\
\text { Problem }\end{array}$ & $\begin{array}{c}\text { Major } \\
\text { Problem }\end{array}$ & $\begin{array}{c}\text { Full } \\
\text { Compl. }\end{array}$ & $\begin{array}{c}\text { Full } \\
\text { Compl. }\end{array}$ & $\begin{array}{c}\text { Full } \\
\text { Compl. }\end{array}$ & $\begin{array}{c}\text { Full } \\
\text { Compl. }\end{array}$ & $\begin{array}{c}\text { Full } \\
\text { Compl. }\end{array}$ & $\begin{array}{c}\text { Full } \\
\text { Compl. }\end{array}$ & $\begin{array}{l}\text { Full } \\
\text { Compl. }\end{array}$ & $\begin{array}{c}\text { Full } \\
\text { Compl. }\end{array}$ & $\begin{array}{l}\text { Full } \\
\text { Compl. }\end{array}$ \\
\hline Public acceptance (6) & No & No & Some & Some & Some & Substantial & Substantial & Substantial & Substantial & Substantial & $\begin{array}{c}\text { Substanti } \\
\text { al } \\
\end{array}$ \\
\hline $\begin{array}{l}\text { Total life cycle cost (in } \\
\text { S millions) }\end{array}$ & $\$ 0$ & $\$ 40$ & $\$ 187$ & $\$ 508$ & $\$ 428$ & $\$ 1,052$ & $\$ 1,096$ & $\$ 1,177$ & $\$ 1,802$ & $\$ 1,141$ & $\$ 614$ \\
\hline \multicolumn{12}{|c|}{$\begin{array}{l}\text { (1) Expected number of cancer fatalities over ten thousand years. } \\
\text { (2) Hazard Index over ten thousand years. } \\
\text { (3) Expected number of cancer fatalities during construction and operation. } \\
\text { (4) Expected number of cancer fatalities during construction and operation. } \\
\text { (5) Constructed measure (see text). } \\
\text { (6) Constructed measure (see text). }\end{array}$} \\
\hline
\end{tabular}




\section{DISTRIBUTION}

No. of

Copies

\section{OFFSITE}

12 DOE/Office of Scientific and Technical Information

\section{ONSITE}

4 DOE Richland Operations Office
J. L. Daily, S7-41
D. J. Francis, S7-53
V. L. Saladin, S7-53
R. W. Unger, S7-53

36 Westinghouse Hanford Company

D. E. Ball, S4-58

P. A. Baynes, B1-58

J. L. Collings, H6-33

G. L. Dunford, S7-81

L. F. Ermold, S7-84

J. S. Garfield, H5-49

K. A. Gasper, G3-21

C. D. Griner, B1-59

M. L. Grygiel (5), B1-59

J. O. Honeyman, S7-81

M. E. Johnson, B1-58

A. K. Lee, B1-58

E. J. Lipke, S7-14

G. A. Meyer, S4-54

W. C. Miller, R1-30

R. J. Murkowski, G6-13

E. C. Norman, B1-59

F. J. Orsag, B1-59

L. G. Peck (5), B1-59

R. W. Powell, G3-21

R. E. Raymond, R2-54
No. of

Copies

Westinghouse Hanford Company (cont.)

D. F. Salsman, B1-59

J. A. Swenson, H5-49

J. D. Thomson, R2-76

A. M. Umek, S7-81

D. J. Washenfelder, H5-27

C. E. Wilson, B1-58

R. D. Wojtasek, S7-84

28 Pacific Northwest Laboratory

G. H. Beeman, S7-71

A. J. Brothers, K8-07

L. L. Dirks, K8-18

A. L. Franklin, K8-07

J. S. Gahimer, (BCO)

M. S. Madden, K8-07

M. A. Robershotte (10), K8-07

D. A. Seaver (5), S7-71

J. C. Traynham, (Ft. Lewis)

C. F. Wend, K8-18

Technical Report Files (5)

Distr.1 